\title{
Serum markers of CYFRA 21-1 and C-reactive proteins in oral squamous cell carcinoma
}

\author{
Yin-Ping Hsu ${ }^{1 \dagger}$, Chia-Hsun Hsieh ${ }^{2 \dagger}$, Hui-Tzu Chien ${ }^{3}$, Chi-Hsiung Lai ${ }^{3}$, Chung-Kan Tsao ${ }^{4}$, Chun-Ta Liao ${ }^{1}$, \\ Chung-Jan Kang ${ }^{1}$, Hung-Ming Wang ${ }^{2}$, Joseph Tung-Chieh Chang ${ }^{5}$ and Shiang-Fu Huang ${ }^{1 *}$
}

\begin{abstract}
Background: CYFRA 21-1 (cytokeratin 19 fragment) and C-reactive proteins (CRP) were separately reported to be associated with prognosis of head and neck squamous cell carcinoma. The combined roles of CYFRA 21-1 and CRP levels were rarely investigated in oral squamous cell carcinoma (OSCC). The purpose of the present study was to analyze the relationship between preoperative levels of both CYFRA 21-1 and CRP, with clinicopathological factors and prognosis in OSCC patients.
\end{abstract}

Methods: A retrospective study was performed on 130 OSCC patients between December 2010 and June 2013. Their serum CYFRA 21-1 and CRP levels were measured preoperatively.

Results: CYFRA $21-1$ level of $\geq 3.3 \mathrm{ng} / \mathrm{mL}$ and CRP level of $\geq 5.0 \mathrm{mg} / \mathrm{L}$ were significantly associated with pathological tumor status $(P<0.001)$, tumor depth ( $>10$ vs. $\leq 10 \mathrm{~mm}, P=0.001)$, bone invasion $(P=0.001)$, skin invasion $(P=0.006)$, pathologic nodal metastasis $(P=0.012)$, and disease-free survival $(P=0.009)$. Higher CYPFRA 21-1 and CRP levels were also associated with higher risks of distant metastasis (log-rank test, $P=0.013$, (HR [95 \% CI]) 1.692 [1.097-2.414]).

Conclusions: Preoperative CYFRA 21-1 and CRP levels are probable candidates as biomarkers for risk stratification in OSCC.

\section{Background}

Oral cavity cancer is one of the commonest cancers in the world but shows wide geographical variation due to habitual consumption of cigarette, alcohol, and areca quid (AQ). The incidence of oral cavity cancer ranks fifth among the types of cancer in Taiwan [1]. Search for significant biomarkers predicting tumor behaviors and patients' prognosis may help clinicians choose appropriate treatment for those patients [2-7]. Newer markers that can help us better and more precisely predict patients' prognosis are needed clinically.

In oral squamous cell carcinoma (OSCC), to early detect tumor, it usually links to the squamous cell component of cancer. Cytokeratins are structural proteins forming the subunits of epithelial intermediary filaments. In the literature, 20 different cytokeratin polypeptides

\footnotetext{
* Correspondence: bigmac@adm.cgmh.org.tw

${ }^{\dagger}$ Equal contributors

'Department of Otolaryngology-Head and Neck Surgery, Chang Gung Memorial Hospital, Chang Gung University, No. 5, Fu-Shin Street, Kwei-Shan, Linkou, Taoyuan 333, Taiwan, Republic of China

Full list of author information is available at the end of the article
}

have been identified. Cytokeratin 19 is expressed by normal and benign epithelial cells and various carcinomas, particularly the lung cancer. CYFRA $21-1$ is the serum soluble fragment of cytokeratin 19 and was first described in the mid 1990s [8]. Increased concentration of CYFRA 21-1 was shown to be associated with poorer prognosis in patients with lung cancer $[9,10]$. The measurement of CYFRA 21-1 in patients with squamous cell carcinoma of the head and neck (HNSCC) is also an established tumor marker and prognosticator [8, 11-17]. CYFRA 21-1 serum levels are significantly higher in patients with HNSCC compared to a healthy or control group [8]. Sawant et al. [18] reported a sensitivity of $84 \%$ and a specificity of $93 \%$ of CYFRA 21-1 in patients with oropharyngeal cancer. They found the serum marker reduced significantly after surgical therapy of the primary tumor.

A second potentially significant marker is the acute phase protein CRP, which has also been shown to correlate with survival in human cancers [3, 19-22]. We previously demonstrated that C-reactive protein (CRP) elevation in OSCC is associated with poor survival and tumor invasiveness $[2,3]$. Elevated CRP could be a marker for chronic 
inflammation in the tumor microenvironment, with chronic inflammation itself also acts as a stimulus for angiogenesis, cell proliferation, and tumorigenesis [23-25]. However, the relationship between CYFRA 21-1 and CRP, and their potential combined value as prognostic markers of survival, has not been previously explored in OSCC. In this study, we retrospectively analyzed 130 OSCC patients who were primarily treated with radical excision in our institution. The aim of this study was to evaluate the importance of CYFRA 21-1 and CRP as tumor markers in patients with OSCC at the time of initial diagnosis in correlation with tumor size, histologic grading, and lymph node metastasis.

\section{Methods}

\section{Patients and staging workup}

We retrospectively reviewed 130 consecutive OSCC patients who had undergone primary radical surgery and were subsequently followed at Chang Gung Memorial Hospital from December 2010 to June 2013. The serum samples were obtained prior to surgery. All patients underwent radical surgery with curative intent. The follow-up for each patient began at the time of cancer treatment and ended at the time of death or last time clinic follow-up, whichever came first.

The patients in this series underwent an extensive preoperative survey, which included a detailed medical history and a complete physical examination, and computed tomography (CT) or magnetic resonance imaging (MRI) scans of the head and neck. Abdominal sonography and bone scan or positron emission tomography (PET) were also included in preoperative tumor survey. The guidelines of the 2010 American Joint Committee on Cancer (AJCC) (tumor-node-metastasis (TNM) classification) were employed for clinical staging [26]. Patients who were initially diagnosed of a distant metastasis were excluded from the analysis.

\section{Treatment}

One hundred twenty-seven participants underwent a wide excision of the primary tumors with $1-\mathrm{cm}$ safe margins (both peripheral and deep margins), which were cryosectioned to ensure that the margin was free from the tumor tissue. Supraomohyoid or modified radical neck dissection was performed according to patients' clinical nodal status. All histological parameters including the depth of infiltration, bone, skin invasion, lymph node extracapsular spread (ECS), and grade of differentiation were recorded.

Postoperative radiotherapy (RT) was performed in patients who presented a stage pT4 tumor, pathologically positive lymph nodes, or pathologically close margins $(\leq 4 \mathrm{~mm})$. Concomitant chemoradiotherapy (CCRT) with cisplatin-based agents was administered to patients with
ECS or pathological multiple lymph node metastases [27, 28]. Three patients received CCRT first, and received salvage radical surgery due to persistence of disease.

\section{Follow-up}

All of the patients had a checkup every month during the first 6 months after treatment, every 2 months during the following 6 months, every 3 months during the

Table 1 Characteristics of the 130 oral cavity squamous cell carcinoma patients

\begin{tabular}{|c|c|}
\hline Characteristic & No. of patients (\%) \\
\hline \multicolumn{2}{|l|}{ Age (years) } \\
\hline Mean & 52.30 \\
\hline Range & $29.0-84.0$ \\
\hline \multicolumn{2}{|l|}{ Gender } \\
\hline Male & $114(87.7)$ \\
\hline Female & $16(12.3)$ \\
\hline \multicolumn{2}{|l|}{ Site of primary tumor } \\
\hline Tongue & $58(44.6)$ \\
\hline Mouth floor & $3(2.3)$ \\
\hline Lip & $5(3.8)$ \\
\hline Buccal mucosa & $44(33.8)$ \\
\hline Alveolar ridge & $13(10.0)$ \\
\hline Hard palate & $0(0)$ \\
\hline Retromolar trigone & $7(5.4)$ \\
\hline \multicolumn{2}{|l|}{ Pathologic tumor status } \\
\hline $\mathrm{T} 1$ & $36(27.7)$ \\
\hline $\mathrm{T} 2$ & $38(29.2)$ \\
\hline T3 & $13(10.0)$ \\
\hline T4a & $30(23.1)$ \\
\hline $\mathrm{T} 4 \mathrm{~b}$ & $13(10.0)$ \\
\hline \multicolumn{2}{|l|}{ Pathologic N stage } \\
\hline No & $68(52.3)$ \\
\hline N1 & $25(19.2)$ \\
\hline $\mathrm{N} 2 \mathrm{~b}$ & $30(23.1)$ \\
\hline $\mathrm{N} 2 \mathrm{C}$ & $7(5.4)$ \\
\hline \multicolumn{2}{|l|}{ Pathologic stage } \\
\hline Stage I & $28(21.5)$ \\
\hline Stage II & $17(13.1)$ \\
\hline Stage III & $23(17.7)$ \\
\hline Stage IV & $62(47.7)$ \\
\hline \multicolumn{2}{|l|}{ Treatment } \\
\hline Surgery alone & $57(43.8)$ \\
\hline Surgery with adjuvant radiation therapy & $12(9.2)$ \\
\hline Surgery with adjuvant chemoradiation therapy & $58(44.6)$ \\
\hline Chemoradiation therapy plus surgery & $3(2.3)$ \\
\hline
\end{tabular}


second year, and every 6 months thereafter. All the patients were subjected to a hemogram, blood chemistry, chest X-ray, and CT scan or MRI in the first 3 and 6 months and then annually afterward. Patients with abnormal clinical symptoms/signs or laboratory data during follow-up would receive a bone scan and liver ultrasound.

\section{Measurement of CYFRA 21-1}

Cytokeratin 19 fragments were detected by the monoclonal antibodies KS 19.1 and BM 19.21; these antibodies are specific for two different epitopes of cytokeratin 19 [29]. The measurement of CYFRA 21-1 was completed in electrochemiluminescent immunoassay (ECLIA) using the CYFRA 21-1 reagent kit. The CYFRA 21-1 concentration of each sample was automatically calculated in a Roche Analytics E170 immunology analyzer. The calculated concentration of CYFRA 21-1 was expressed in $\mathrm{ng} / \mathrm{mL}$, and the cut-off level of $3.3 \mathrm{ng} / \mathrm{mL}$ was used according to the manufacturer's instructions (Roche Diagnostics, Mannheim, Germany) [30]. CYFRA 21-1 serum levels were determined for each patient at the time of initial diagnosis.

\section{Measurement of CRP}

Preoperative serum CRP levels were checked at the time of tissue diagnosis before any medical intervention or

Table 2 The associations between preoperative CRP, CYFRA 21-1, and clinicopathologic parameters $(N=130)$

\begin{tabular}{|c|c|c|c|c|c|c|}
\hline & \multicolumn{3}{|c|}{ CRP } & \multicolumn{3}{|c|}{ CYFRA 21-1 } \\
\hline & Negative $(n(\%))$ & Positive (n (\%)) & $P$ value & Negative $(n(\%))$ & Positive (n (\%)) & $P$ value \\
\hline \multicolumn{7}{|l|}{ Pathologic tumor status } \\
\hline Early $^{\mathrm{a}}(n=74)$ & $64(86.5)$ & $10(13.5)$ & $<0.001^{e}$ & $66(89.2)$ & $8(10.8)$ & 0.308 \\
\hline Advanced $^{\mathrm{b}}(n=56)$ & $29(51.8)$ & $27(48.2)$ & & $46(82.1)$ & $10(17.9)$ & \\
\hline \multicolumn{7}{|l|}{ Pathologic N stage } \\
\hline NO $(n=68)$ & $54(79.4)$ & $14(20.6)$ & 0.049 & $59(86.8)$ & $9(13.2)$ & 0.024 \\
\hline N1 $(n=25)$ & $18(72.0)$ & $7(28.0)$ & & $25(100.0)$ & $0(0.0)$ & \\
\hline $\mathrm{N} 2(n=37)$ & $21(56.8)$ & $16(43.2)$ & & $28(75.7)$ & $9(24.3)$ & \\
\hline \multicolumn{7}{|l|}{ Nodal status } \\
\hline$(-)$ metastasis, $(-)$ ECS $(n=68)$ & $54(79.4)$ & $14(20.6)$ & 0.014 & $59(86.8)$ & $9(13.2)$ & 0.039 \\
\hline$(+)$ metastasis, $(-)$ ECS $(n=23)$ & $18(78.3)$ & $5(21.7)$ & & $23(100.0)$ & $0(0.0)$ & \\
\hline$(+)$ metastasis, $(+)$ ECS $(n=39)$ & $21(53.8)$ & $18(46.2)$ & & $30(76.9)$ & $9(23.1)$ & \\
\hline \multicolumn{7}{|l|}{ Differentiation } \\
\hline Well $(n=32)$ & $21(65.6)$ & $11(34.4)$ & 0.304 & 29 (90.6) & $3(9.4)$ & 0.689 \\
\hline Moderate $(n=80)$ & $61(76.2)$ & $19(23.8)$ & & $68(85.0)$ & $12(15.0)$ & \\
\hline Poor $(n=18)$ & $11(61.1)$ & $7(38.9)$ & & $15(83.3)$ & $3(16.7)$ & \\
\hline \multicolumn{7}{|l|}{ Tumor stage } \\
\hline Early $^{c}(n=45)$ & $40(88.9)$ & $5(11.1)$ & $0.002^{\mathrm{e}}$ & $38(84.4)$ & $7(15.6)$ & $0.791^{e}$ \\
\hline Advanced $^{\mathrm{d}}(n=85)$ & $53(62.4)$ & $32(37.6)$ & & $74(87.1)$ & $11(12.9)$ & \\
\hline \multicolumn{7}{|l|}{ Skin invasion } \\
\hline No $(n=117)$ & $88(75.2)$ & $29(24.8)$ & $0.009^{e}$ & $102(87.2)$ & $15(12.8)$ & $0.389^{e}$ \\
\hline Yes $(n=13)$ & $5(38.5)$ & $8(61.5)$ & & $10(76.9)$ & $3(23.1)$ & \\
\hline \multicolumn{7}{|l|}{ Bone invasion } \\
\hline No $(n=105)$ & $83(79.0)$ & $22(21.0)$ & $<0.001^{\mathrm{e}}$ & 91 (86.7) & $14(13.3)$ & $0.750^{\mathrm{e}}$ \\
\hline Yes $(n=25)$ & $10(40.0)$ & $15(60.0)$ & & $21(84.0)$ & $4(16.0)$ & \\
\hline \multicolumn{7}{|l|}{ Tumor depth $\geq 10 \mathrm{~mm}$} \\
\hline No $(n=60)$ & $53(88.3)$ & $7(11.7)$ & $<0.001^{\mathrm{e}}$ & $54(90.0)$ & $6(10.0)$ & $0.311^{e}$ \\
\hline Yes $(n=70)$ & $40(57.1)$ & 30 (42.9) & & 58 (82.9) & $12(17.1)$ & \\
\hline
\end{tabular}

ECS extracapsular spread

a 1 - T2

${ }^{\mathrm{b}} \mathrm{T} 3-\mathrm{T} 4$

'Stage I-II

dStage III-IV

'Fisher's exact test 

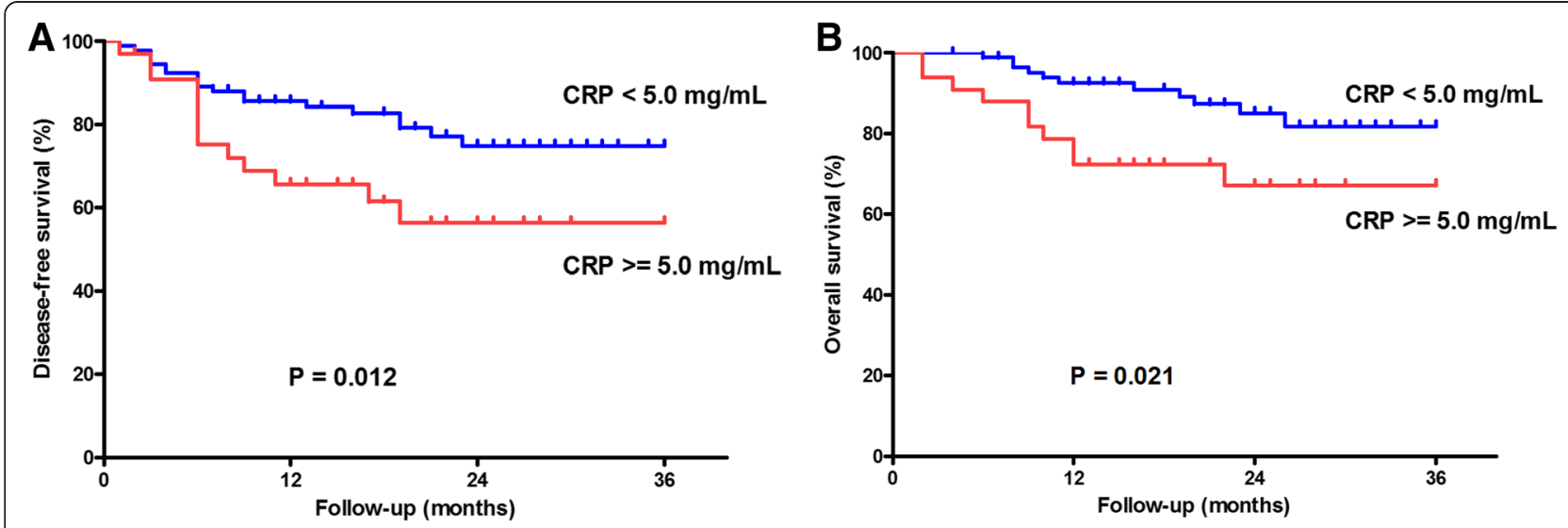

Fig. 1 Survival curves in 130 OSCC patients related to the preoperative CRP level. a The lower CRP group ( $<5.0 \mathrm{mg} / \mathrm{L})$ showed significantly better DFS compared to the higher CRP level group $(\geq 5.0 \mathrm{mg} / \mathrm{L})(P=0.012)$. $\mathbf{b}$ The lower CRP group showed significantly better OS compared to the higher CRP level group $(P=0.021)$

antibiotic treatment to minimize intra-individual differences. A fresh blood sample was collected and sent to the laboratory for testing. Serum CRP levels were detected using an auto-analyzer (Hitachi 7600-210, Hitachi Medico, Tokyo). The cut-off point for serum CRP was set at $5.0 \mathrm{mg} / \mathrm{L}$, which is internationally adopted for inflammation $[3,5,31]$.

\section{Ethics}

The study was approved by the Institutional Review Board (103-3590B) of Chang Gung Memorial Hospital, Linkou, Taiwan, ROC.

\section{Results}

Patient characteristics

Table 1 shows the clinicopathological characteristics of the 130 OSCC patients (114 males and 16 females). The tongue $(N=58,44.6 \%)$ and the buccal mucosa $(N=44$,
$33.8 \%)$ were the most common primary tumor sites. The tumor stage distribution was $28(21.5 \%)$ in stage I, 17 (13.1\%) in stage II, $23(17.7 \%)$ in stage III, and 62 $(47.7 \%)$ in stage IV. The median follow-up period was 19.0 months. All patients received radical surgeries, and the adjuvant therapies were listed in Table 1. All patients were followed in clinic at least 6 months after treatment.

\section{CRP levels, clinicopathological variables, and prognosis}

Elevated CRP levels (CRP $\geq 5.0 \mathrm{mg} / \mathrm{L}$ ) were found to be associated with the skin invasion $(P=0.009)$, bone invasion $(P<0.001)$, tumor depth $(\geq 10$ vs. $<10 \mathrm{~mm}, P<0.001)$, pathological tumor status $(P<0.001)$, and pathologic nodal metastasis $(P=0.049)$ (Table 2). Higher CRP level was also found to be related with lymph node metastasis with ECS $(P=0.014)$.

When comparing the survival differences between the higher CRP group (CRP $\geq 5.0 \mathrm{mg} / \mathrm{L})$ and lower CRP
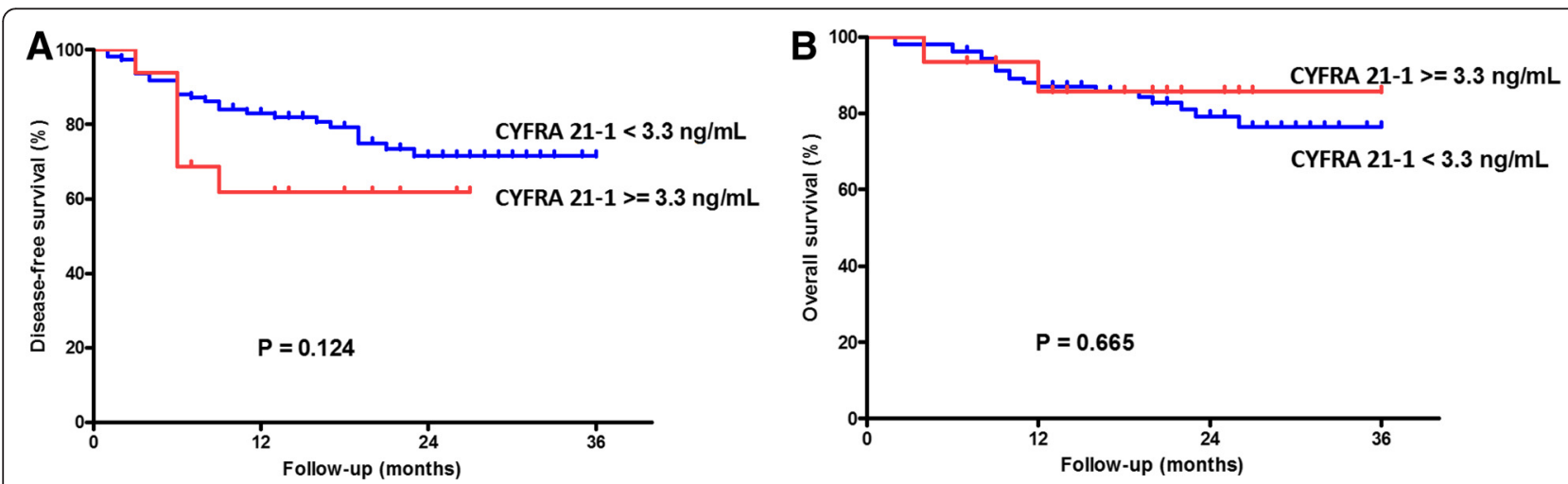

Fig. 2 Survival curves in 130 OSCC patients related to the preoperative CYFRA 21-1. a The lower CYFRA 21-1 group ( $<3.3 \mathrm{ng} / \mathrm{mL})$ showed better DFS compared to the higher CYFRA 21-1 level group ( $\geq 3.3 \mathrm{ng} / \mathrm{mL})(P=0.124)$. b The lower CYFRA 21-1 group showed similar OS compared to the higher CYFRA 21-1 level group $(P=0.665)$ 
group (CRP $<5.0 \mathrm{mg} / \mathrm{L}$ ), the disease-free survival (DFS) was significantly better in the latter than that of the former group (log-rank test, $P<0.012$, Fig. 1a). In addition, in the higher CRP group (CRP $\geq 5.0 \mathrm{mg} / \mathrm{L})$, the overall survival (OS) was also remarkably worse than that in the lower CRP group (CRP $<5.0 \mathrm{mg} / \mathrm{L})$ (log-rank test, $P=0.021$, Fig. $1 \mathrm{~b}$ ).

\section{CYFRA 21-1 level and its relation with clinicopathological} variables and prognosis

A higher CYFRA $21-1$ level (CYFRA $21-1 \geq 3.3 \mathrm{ng} / \mathrm{mL}$ ) was statistically related with pathological nodal status $(P=$ $0.024)$ and nodal ECS $(P=0.039)$. However, elevated
CYFRA 21-1 level was not related with bone invasion, skin invasion, and tumor depth (Table 2).

The DFS was insignificantly worse in the higher CYFRA 21-1 level group (CYFRA $21-1 \geq .3 \mathrm{ng} / \mathrm{mL}$ ) than that of the lower CYFRA 21-1 level group (CYFRA $21-1<3.3 \mathrm{ng} / \mathrm{mL}$ ) (log-rank test, $P=0.124$, Fig. 2a). In addition, the OS was neither associated with the CYFRA 21-1 level (log-rank test, $P=0.665$, Fig. 2b).

\section{Combined CRP and CYFRA 21-1 level and its relation with} clinicopathological variables and prognosis

CRP level was related with CYFRA 21-1 level in linear correlation $(P=0.010)$. A higher CYFRA 21-1 level was

Table 3 The associations between preoperative CRP, CYFRA 21-1, and clinicopathologic parameters $(N=130)$

\begin{tabular}{|c|c|c|c|c|c|}
\hline & $\begin{array}{c}\text { CRP }(-), \text { CYFRA 21-1 (-) } \\
(n(\%))\end{array}$ & $\begin{array}{c}\text { CRP }(-), \text { CYFRA 21-1 (+) } \\
(n(\%))\end{array}$ & $\begin{array}{c}\text { CRP }(+), \text { CYFRA 21-1 (-) } \\
(n(\%))\end{array}$ & $\begin{array}{c}\text { CRP }(+), \text { CYFRA 21-1 (+) } \\
(n(\%))\end{array}$ & $P$ value \\
\hline \multicolumn{6}{|l|}{ Tumor stage } \\
\hline Early $^{\mathrm{a}}(n=45)$ & $33(73.3)$ & $7(15.6)$ & $5(11.1)$ & $0(0.0)$ & \multirow[t]{2}{*}{$0.009^{e}$} \\
\hline Advanced $^{\mathrm{b}}(n=85)$ & $52(61.2)$ & $1(1.2)$ & $22(25.9)$ & $10(11.8)$ & \\
\hline \multicolumn{6}{|l|}{ Pathologic N stage } \\
\hline No $(n=68)$ & $47(69.1)$ & $7(10.3)$ & $12(17.6)$ & $2(2.9)$ & \multirow[t]{3}{*}{$0.012^{\mathrm{e}}$} \\
\hline $\mathrm{N} 1(n=25)$ & $18(72.0)$ & $0(0.0)$ & $7(28.0)$ & $0(0.0)$ & \\
\hline $\mathrm{N} 2(n=37)$ & $20(54.1)$ & $1(2.7)$ & $8(21.6)$ & $8(21.6)$ & \\
\hline \multicolumn{6}{|l|}{ Nodal status } \\
\hline$(-)$ metastasis, $(-)$ ECS $(n=68)$ & $47(69.1)$ & $7(10.3)$ & $12(17.6)$ & $2(2.9)$ & \multirow[t]{3}{*}{$0.006^{\mathrm{e}}$} \\
\hline$(+)$ metastasis, $(-)$ ECS $(n=23)$ & $18(78.3)$ & $0(0.0)$ & $5(21.7)$ & $0(0.0)$ & \\
\hline$(+)$ metastasis, $(+)$ ECS $(n=39)$ & $20(51.3)$ & $1(2.6)$ & $10(25.6)$ & $8(20.5)$ & \\
\hline \multicolumn{6}{|l|}{ Differentiation } \\
\hline Well $(n=32)$ & $20(62.5)$ & $1(3.1)$ & $9(28.1)$ & $2(6.2)$ & \multirow[t]{3}{*}{0.734} \\
\hline Moderate $(n=80)$ & $55(68.8)$ & $6(7.5)$ & $13(16.2)$ & $6(7.5)$ & \\
\hline Poor $(n=18)$ & $10(55.6)$ & $1(5.6)$ & $5(27.8)$ & $2(11.1)$ & \\
\hline \multicolumn{6}{|l|}{ Pathologic tumor status } \\
\hline Early $^{c}(n=74)$ & $56(75.7)$ & $8(10.8)$ & $10(13.5)$ & $0(0.0)$ & \multirow[t]{2}{*}{$<0.001^{\mathrm{e}}$} \\
\hline Advanced $^{d}(n=56)$ & $29(51.8)$ & $0(0.0)$ & $17(30.4)$ & $10(17.9)$ & \\
\hline \multicolumn{6}{|l|}{ Skin invasion } \\
\hline No $(n=117)$ & $80(68.4)$ & $8(6.8)$ & $22(18.8)$ & $7(6.0)$ & \multirow[t]{2}{*}{$0.006^{\mathrm{e}}$} \\
\hline Yes $(n=13)$ & $5(38.5)$ & $0(0.0)$ & $5(38.5)$ & $3(23.1)$ & \\
\hline \multicolumn{6}{|l|}{ Bone invasion } \\
\hline No $(n=105)$ & $75(71.4)$ & $8(7.6)$ & $16(15.2)$ & $6(5.7)$ & \multirow[t]{2}{*}{$0.001^{e}$} \\
\hline Yes $(n=25)$ & $10(40.0)$ & $0(0.0)$ & $11(44.0)$ & $4(16.0)$ & \\
\hline \multicolumn{6}{|l|}{ Tumor depth $\geq 10 \mathrm{~mm}$} \\
\hline No $(n=60)$ & $47(78.3)$ & $6(10.0)$ & $7(11.7)$ & $0(0.0)$ & \multirow[t]{2}{*}{$<0.001^{\mathrm{e}}$} \\
\hline Yes $(n=70)$ & $38(54.3)$ & $2(2.9)$ & $20(28.6)$ & $10(14.3)$ & \\
\hline \multicolumn{6}{|l|}{ 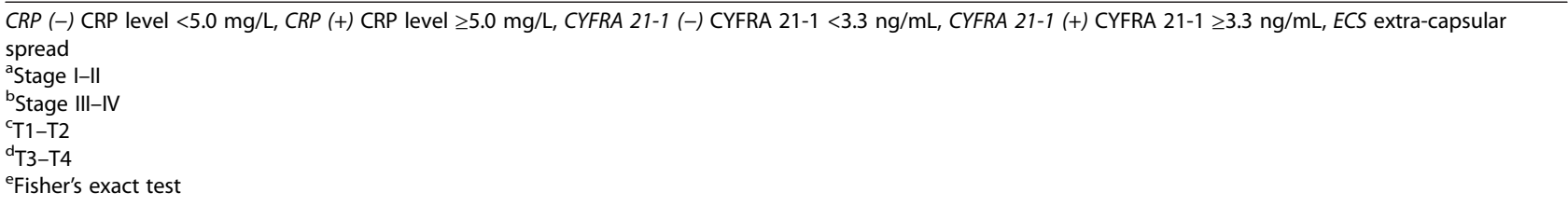 } \\
\hline
\end{tabular}


accompanied by a higher serum CRP level. When the patients were divided into four groups according to the preoperative higher or lower CYFRA 21-1 and CRP levels, a close association was observed between a coexistence of higher CYFRA 21-1 $(\geq 3.3 \mathrm{ng} / \mathrm{mL})$ and higher CRP $(\geq 5.0 \mathrm{mg} / \mathrm{L})$ status and pathological tumor status $\left(\chi^{2}\right.$ trend test $P<0.001)$, pathologic nodal metastasis $\left(\chi^{2}\right.$ trend test $P=0.012)$, tumor stage $(P=0.009)$, bone invasion $(P=0.001)$, skin invasion $(P=0.006)$, and tumor depth ( $\geq 10$ vs. $<10 \mathrm{~mm}, P<0.001$ ) (Table 3 ).

When the survival rates of the four groups were compared, the DFS of the higher CYFRA 21-1 and higher CRP level group was significantly lower than that of the other groups (log-rank test, $P=0.009$, Fig. 3a). In addition, the OS was lower in the same group than that in the other groups (log-rank test, $P=0.098$, Fig. 3b) but does not reach statistical significance (Table 4).

\section{Discussion}

Deng et al. analyzed 142 HNSCC cases, and they found that the positive rates of CYFRA 21-1 increased with progression of HNSCC; serum CYFRA 21-1 levels were related to the primary tumor status and nodal status $(N)(P<0.001)$, but not related to patient age, gender, smoking and drinking habit, or histopathological grade $(P>0.05)$. The CYFRA $21-1$ in HNSCC decreased significantly $(P<0.001)$ after treatment [30]. Doweck et al. reported that CYFRA 21-1 can be used in HNSCC at a sensitivity of $60 \%$, with a good correlation with tumor stage and an inverse correlation with the grade of tumor differentiation [14]. They suggested that CYFRA 21-1 was a good marker for HNSCC. In our study, CYFRA 21-1 was not associated with bone, skin, or perineural invasion. The only significant parameter is the lymph node metastasis. It implies that CYFRA 21-1 could be released into the bloodstream by metastatic tumor cells.

Regarding the role of CYFRA 21-1 in predicting prognosis, the results are positive in the literature $[14,32]$. However, the prognostic role of CYFRA 21-1 in our study was statistically insignificant. There are two possible reasons: one is low sensitivity rate of elevated CYFRA 21-1. Eighteen patients (13.85\%) were found with elevated CYPFRA 21-1. The other is the cut-off values of CYFRA 21-1 in the literature are different. The results could be different when choosing different cut-off points. It is also apparent that there is contradictory information emerging from different laboratories. In Wang et al.'s review, different methods in the detection of CYFRA 21-1 including immunoradiometric assay, ECLIA, and enzyme-linked immunosorbent assay (ELISA) were used in the literature [33]. The use of CYFRA 21-1 in detecting OSCC could be limited because the increase in CYFRA 21-1 provides low sensitivity [18].

Serum CYFRA 21-1 level was linearly associated with CRP level $(P=0.010)$. As seen in the results, the elevated CRP was associated with bone invasion, skin invasion, and lymph node metastasis. CRP was elevated due to peri-tumor tissue destruction or lymph node metastasis. When we combined these two markers, a strong correlation was found between both higher CYPFRA 21-1 and CRP levels and tumor stage, nodal metastasis, skin invasion, and bone invasion (Table 3). In OSCC patients with lymph node metastasis, the serum CYPFRA 21-1 and CRP could be useful in stratifying the patients.

Regarding patients' survival, simultaneous elevation of the CYPFRA 21-1 and CRP level was related with worse DFS and OS in univariate analysis. Another prognostic end point is the interval between treatment and distant

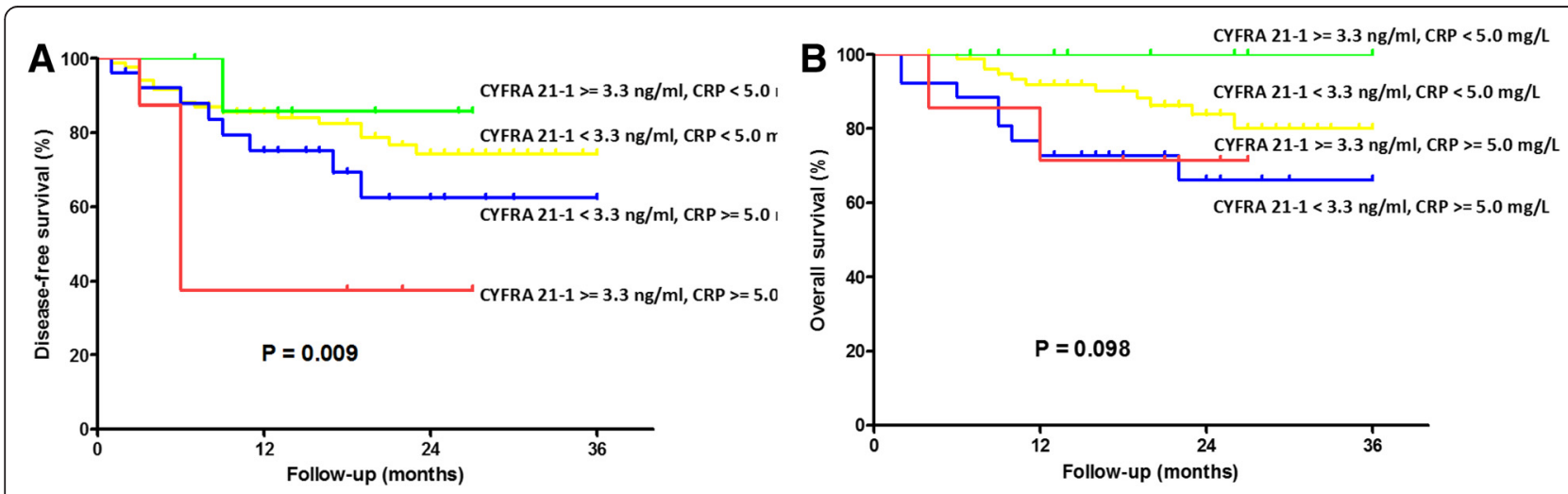

Fig. 3 Survival curves in 130 OSCC patients related to the preoperative CRP and CYFRA 21-1 level. a The lower CRP and lower CYFRA 21-1 level group showed significantly better DFS compared to the higher CRP and higher CYFRA 21-1 level group $(P=0.009)$. $\mathbf{b}$ The lower CRP and lower CYFRA 21-1 level group showed significantly better OS compared to the higher CRP and higher CYFRA 21-1 level group $(P=0.098)$ 
Table 4 Univariate log-rank test of prognostic covariates in 130 patients with oral cavity squamous cell carcinoma regarding disease-free and overall survival

\begin{tabular}{|c|c|c|}
\hline & DFS, $P$ value & OS, $P$ value \\
\hline & {$[\mathrm{HR}(95 \% \mathrm{Cl})]$} & {$[\mathrm{HR}(95 \% \mathrm{CI})]$} \\
\hline \multicolumn{3}{|l|}{ Age (years) } \\
\hline$<50$ & 0.251 & 0.885 \\
\hline$\geq 50$ & $0.678(0.349-1.316)$ & $0.938(0.395-2.228)$ \\
\hline \multicolumn{3}{|l|}{ Sex } \\
\hline Female & 0.776 & 0.164 \\
\hline Male & $1.163(0.411-3.297)$ & $0.490(0.179-1.337)$ \\
\hline \multicolumn{3}{|l|}{ Nodal status } \\
\hline$(-)$ metastasis, $(-)$ ECS & 0.001 & 0.008 \\
\hline$(+)$ metastasis, $(-)$ ECS & $1.193(0.384-3.705)$ & $1.858(0.463-7.447)$ \\
\hline (+) metastasis, (+) ECS & $3.586(1.733-7.420)$ & $4.618(1.729-12.338)$ \\
\hline \multicolumn{3}{|l|}{ Differentiation } \\
\hline Well/moderate & 0.027 & 0.041 \\
\hline Poor & $2.437(1.105-5.372)$ & $2.868(1.043-7.886)$ \\
\hline \multicolumn{3}{|l|}{ Pathologic tumor status } \\
\hline Early $^{a}$ & 0.023 & 0.096 \\
\hline Advanced $^{\mathrm{b}}$ & $2.172(1.111-4.247)$ & $2.084(0.877-4.949)$ \\
\hline \multicolumn{3}{|l|}{ CRP } \\
\hline$<5 \mathrm{mg} / \mathrm{mL}$ & 0.016 & 0.027 \\
\hline$\geq 5 \mathrm{mg} / \mathrm{mL}$ & $2.274(1.163-4.448)$ & $2.636(1.118-6.217)$ \\
\hline \multicolumn{3}{|l|}{ Cyfra 21-1 } \\
\hline$<3.3 \mathrm{ng} / \mathrm{mL}$ & 0.135 & 0.667 \\
\hline$\geq 3.3 \mathrm{ng} / \mathrm{mL}$ & $1.885(0.821-4.328)$ & $0.726(0.169-3.120)$ \\
\hline \multicolumn{3}{|l|}{ Tumor depth } \\
\hline$<10 \mathrm{~mm}$ & 0.030 & 0.052 \\
\hline$\geq 10 \mathrm{~mm}$ & $2.207(1.080-4.510)$ & $2.560(0.991-6.613)$ \\
\hline Cyfra 21-1 and CRP & 0.019 & 0.235 \\
\hline Cyfra 21-1 $<3.3 \mathrm{ng} / \mathrm{mL}$, CRP $<5 \mathrm{mg} / \mathrm{L}$ & 1 & 1 \\
\hline Cyfra 21-1 $\geq 3.3 \mathrm{ng} / \mathrm{mL}, C R P<5 \mathrm{mg} / \mathrm{L}$ & $0.575(0.077-4.300)$ & $0.000(0.000)$ \\
\hline Cyfra 21-1 $<3.3 \mathrm{ng} / \mathrm{mL}, C R P \geq 5 \mathrm{mg} / \mathrm{L}$ & $1.683(0.761-3.722)$ & $2.578(1.036-6.414)$ \\
\hline Cyfra 21-1 $\geq 3.3 \mathrm{ng} / \mathrm{mL}, C R P \geq 5 \mathrm{mg} / \mathrm{L}$ & $4.065(1.610-10.261)$ & $1.928(0.426-8.726)$ \\
\hline
\end{tabular}

ECS extra-capsular spread

${ }^{\mathrm{a}} \mathrm{T} 1-\mathrm{T} 2$

bT3-T4

metastasis. We found that patients with higher CYPFRA 21-1 and CRP levels carry higher risks of distant metastasis (Fig. 4, log-rank test, $P=0.013$, HR [95 \% CI] 1.692 [1.097-2.414]). The elevation of CYPFRA 21-1 could be from the release of tumor antigen into the blood stream. Host immune system responds to tumor growth with elevated inflammatory cytokines (such as interleukin-6) and subsequently elevates the serum CRP levels [34]. The association of higher CYPFRA 21-1 and CRP with distant metastasis could be attributed to the advanced tumor stage or the existence of circulating tumor cells. Combination of these two markers provides clinicians clues of worse prognosis in OSCCs before surgeries.

We demonstrated that elevated CYFRA 21-1 levels in OSCC predicted nodal metastases in OSCC patients. The present study has further demonstrated the use of combined CYFRA 21-1 and CRP as a prognostic marker in OSCC and may be significant as a biomarker to predict prognosis and stratify patients for adjuvant therapies in the absence of traditional indications such as lymph node 


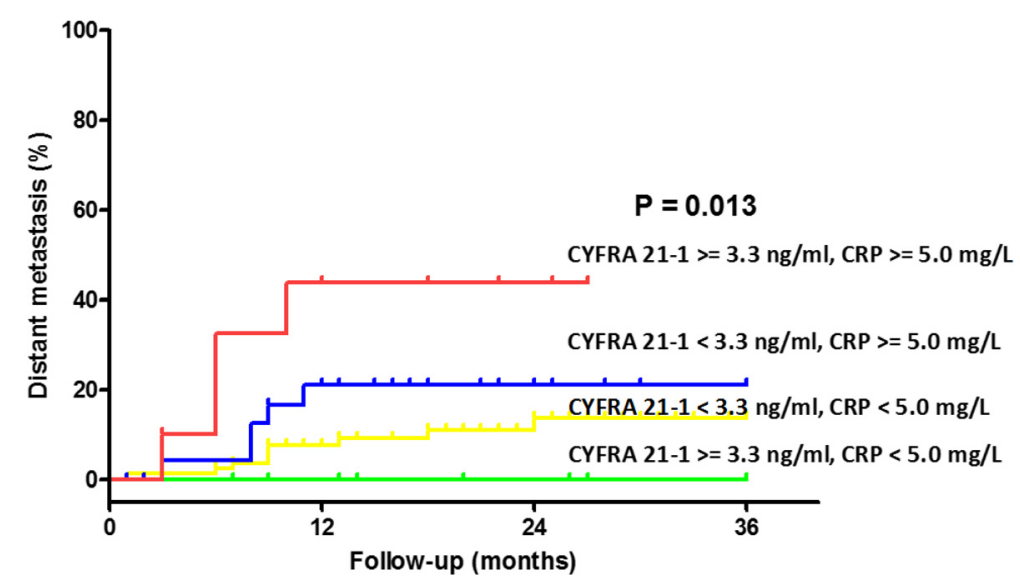

Fig. 4 Distant metastatic rates in 130 OSCC patients related to the preoperative CRP and CYFRA 21-1 level. The higher CRP and higher CYFRA 21-1 level group showed significantly higher distant metastatic rate compared to the lower CRP or lower CYFRA 21-1 level group ( $P=0.013)$

ECS. In this study, the follow-up period was relatively short and patient number was not large. In multivariate adjustment, the prognostic role of combined CYPFRA 211 and CRP in our analysis does not reach statistical significance. Our present study per se is preliminary. Further work and longer follow-up are required to elucidate the exact molecular mechanisms and clinical application of CYFRA 21-1 and CRP in OSCC.

\section{Conclusions}

Preoperative CYFRA 21-1 serum concentration was related with lymph node metastasis. CRP level predicts greater extent of tumor destruction including bone invasion, skin invasion, tumor status, and lymph node metastasis. Combining the CYPFRA 21-1 and CRP levels predicts higher risks of disease recurrence and distant metastasis. Preoperative CYFRA 21-1 and CRP levels are thus probable candidates as biomarkers for risk stratification in OSCC.

\section{Competing interests}

The authors declare that they have no competing interests.

\section{Authors' contributions}

$\mathrm{YPH}, \mathrm{CHH}$, and SFH conceived the idea for the manuscript, conducted a literature search, and drafted the manuscript. SFH organized the manuscript and critically revised the manuscript. CTL, CKT, HMW, CJK, and JTCC collected the data. HTC and CHL analyzed the data. HTC plotted the figures. HMW, CKT, and JTCC critically revised the manuscript. All authors read and approved the final manuscript.

\section{Acknowledgements}

The authors thank all the members of the Cancer Center, Chang Gung Memorial Hospital, Linkou, Taiwan, for their invaluable help.

\section{Author details}

${ }^{1}$ Department of Otolaryngology-Head and Neck Surgery, Chang Gung Memorial Hospital, Chang Gung University, No. 5, Fu-Shin Street, Kwei-Shan, Linkou, Taoyuan 333, Taiwan, Republic of China. ${ }^{2}$ Department of Medical Oncology, Chang Gung Memorial Hospital, Chang Gung University, Taoyuan, Taiwan, Republic of China. ${ }^{3}$ Department of Public Health, Chang Gung
University, Taoyuan, Taiwan, Republic of China. ${ }^{4}$ Department of Plastic and Reconstructive Surgery, Chang Gung Memorial Hospital Linkou Medical Center, Chang Gung University, Taoyuan, Taiwan, Republic of China. ${ }^{5}$ Department of Radiation Oncology, Chang Gung Memorial Hospital, Chang Gung University, Taoyuan, Taiwan, Republic of China.

Received: 5 June 2015 Accepted: 20 July 2015

Published online: 21 August 2015

\section{References}

1. Cancer registry annual report in Taiwan area. Department of Health, the Executive Yuan, Taiwan, R.O.C. 2009.

2. Lin WH, Chen IH, Wei FC, Huang JJ, Kang CJ, Hsieh LL, et al. Clinical significance of preoperative squamous cell carcinoma antigen in oral-cavity squamous cell carcinoma. Laryngoscope. 2011;121:971-7.

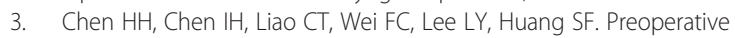
circulating C-reactive protein levels predict pathological aggressiveness in oral squamous cell carcinoma: a retrospective clinical study. Clin Otolaryngol. 2011;36:147-53.

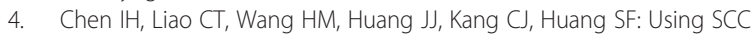
antigen and CRP levels as prognostic biomarkers in recurrent oral cavity squamous cell carcinoma. PLOS ONE 2014, in press.

5. Huang SF, Wei FC, Liao CT, Wang HM, Lin CY, Lo S, et al. Risk stratification in oral cavity squamous cell carcinoma by preoperative CRP and SCC antigen levels. Ann Surg Oncol. 2012;19:3856-64.

6. Rentoft M, Coates PJ, Loljung L, Wilms T, Laurell G, Nylander K. Expression of CXCL10 is associated with response to radiotherapy and overall survival in squamous cell carcinoma of the tongue. Tumour Biol. 2014;35:4191-8.

7. Toyoda M, Kaira K, Ohshima Y, Ishioka NS, Shino M, Sakakura K, et al. Prognostic significance of amino-acid transporter expression (LAT1, ASCT2, and $x(T)$ in surgically resected tongue cancer. Br J Cancer. 2014;110:2506-13.

8. Niemann AM, Goeroegh T, Gottschlich S, Lippert BM, Werner JA. Cut-off value determination of CYFRA 21-1 for squamous cell carcinomas of the head and neck (SCCHN). Anticancer Res. 1997;17:2859-60.

9. Muley T, Fetz TH, Dienemann H, Hoffmann H, Herth FJ, Meister M, et al. Tumor volume and tumor marker index based on CYFRA 21-1 and CEA are strong prognostic factors in operated early stage NSCLC. Lung Cancer. 2008;60:408-15

10. Tomita M, Shimizu T, Ayabe T, Yonei A, Onitsuka T. Prognostic significance of tumour marker index based on preoperative CEA and CYFRA 21-1 in non-small cell lung cancer. Anticancer Res. 2010;30:3099-102.

11. Al Shagahin H, Alkotyfan K, Muller HH, Sesterhenn AM, Werner JA. Cyfra 21-1 as a serum tumor marker for follow-up of patients with laryngeal and hypopharyngeal squamous cell carcinoma. Anticancer Res. 2009;29:3421-5 
12. Banal A, Hacene K, Berthelot-Ruff E, Mahe E, Fontana X, Pichon MF. Comparison of Cyfra 21-1 and SCC assays in head and neck tumours. Tumour Biol. 2001;22:27-35.

13. Boucek J, Mrkvan T, Chovanec M, Kuchar M, Betka J, Boucek V, et al. Regulatory $T$ cells and their prognostic value for patients with squamous cell carcinoma of the head and neck. J Cell Mol Med. 2010;14:426-33.

14. Doweck I, Barak M, Greenberg E, Uri N, Kellner J, Lurie M, et al. Cyfra 21-1. A new potential tumor marker for squamous cell carcinoma of head and neck. Arch Otolaryngol Head Neck Surg. 1995;121:177-81.

15. Kuropkat C, Lippert BM, Werner JA. Follow-up with serum Cyfra 21-1 in patients with squamous cell carcinomas of the head and neck. Oncology. 2002;63:280-5

16. Kuropkat C, Werner JA. Analytical and clinical evaluation of CYFRA 21-1 by electrochemiluminescent immunoassay in head and neck squamous cell carcinoma. J Laryngol Otol. 2003;117:1007-8. author reply 1008-1009.

17. Zhong LP, Zhu HG, Zhang CP, Chen WT, Zhang ZY. Detection of serum Cyfra 21-1 in patients with primary oral squamous cell carcinoma. Int J Oral Maxillofac Surg. 2007;36:230-4.

18. Sawant SS, Zingde SM, Vaidya MM. Cytokeratin fragments in the serum: their utility for the management of oral cancer. Oral Oncol. 2008;44:722-32.

19. Allin $\mathrm{KH}$, Bojesen SE, Nordestgaard BG. Baseline C-reactive protein is associated with incident cancer and survival in patients with cancer. J Clin Oncol. 2009;27:2217-24.

20. Mahmoud FA, Rivera NI. The role of C-reactive protein as a prognostic indicator in advanced cancer. Curr Oncol Rep. 2002;4:250-5.

21. McMillan DC, Elahi MM, Sattar N, Angerson WJ, Johnstone J, McArdle CS. Measurement of the systemic inflammatory response predicts cancer-specific and non-cancer survival in patients with cancer. Nutr Cancer. 2001:41:64-9.

22. Suh SY, Ahn HY. A prospective study on C-reactive protein as a prognostic factor for survival time of terminally ill cancer patients. Support Care Cancer. 2007;15:613-20.

23. Balkwill F, Mantovani A. Inflammation and cancer: back to Virchow? Lancet. 2001;357:539-45

24. Coussens LM, Werb Z. Inflammation and cancer. Nature. 2002:420:860-7.

25. Gunter MJ, Stolzenberg-Solomon R, Cross AJ, Leitzmann MF, Weinstein S, Wood RJ, et al. A prospective study of serum C-reactive protein and colorectal cancer risk in men. Cancer Res. 2006;66:2483-7.

26. Edge SB, Compton CC. The American Joint Committee on Cancer: the 7th edition of the AJCC cancer staging manual and the future of TNM. Ann Surg Oncol. 2010;17:1471-4.

27. Huang SF, Kang CJ, Lin CY, Fan KH, Yen TC, Wang HM, et al. Neck treatment of patients with early stage oral tongue cancer: comparison between observation, supraomohyoid dissection, and extended dissection. Cancer 2008; 112:1066-75

28. Liao CT, Chang JT, Wang HM, Ng SH, Hsueh C, Lee LY, et al. Analysis of risk factors of predictive local tumor control in oral cavity cancer. Ann Surg Oncol 2008; 15:915-22.

29. Bodenmuller H, Ofenloch-Hahnle B, Lane EB, Dessauer A, Bottger V, Donie F. Lung cancer-associated keratin 19 fragments: development and biochemical characterisation of the new serum assay Enzymun-Test CYFRA 21-1. Int J Biol Markers. 1994;9:75-81.

30. Deng $Y F$, Chen $P$, Lin $Y Z$, Le JZ, Wu XL, Yu MQ, et al. Analytical and clinical evaluation of CYFRA 21-1 by electrochemiluminescent immunoassay in head and neck squamous cell carcinoma. J Laryngol Otol. 2003;117:190-4.

31. Fang HY, Huang XY, Chien HT, Chang JT, Liao CT, Huang JJ, et al. Refining the role of preoperative C-reactive protein by neutrophil/lymphocyte ratio in oral cavity squamous cell carcinoma. Laryngoscope. 2013;123:2690-9.

32. Bongers V, Braakhuis BJ, Snow GB. Circulating fragments of cytokeratin 19 in patients with head and neck squamous cell carcinoma. Clin Otolaryngol Allied Sci. 1995;20:479-82.

33. Wang YX, Hu D, Yan X. Diagnostic accuracy of Cyfra 21-1 for head and neck squamous cell carcinoma: a meta-analysis. Eur Rev Med Pharmacol Sci. 2013;17:2383-9.

34. Baron JA. Epidemiology of non-steroidal anti-inflammatory drugs and cancer. Prog Exp Tumor Res. 2003:37:1-24.

\section{Submit your next manuscript to BioMed Central and take full advantage of:}

- Convenient online submission

- Thorough peer review

- No space constraints or color figure charges

- Immediate publication on acceptance

- Inclusion in PubMed, CAS, Scopus and Google Scholar

- Research which is freely available for redistribution 